\title{
Tradição e Inovação: provocações
} Tradition and Innovation: provocations

Cariad Astles ${ }^{1}$ 


\section{Resumo}

O que pode ser dito de forma útil sobre tradição e inovação? Este artigo questiona se esses termos são realmente os mais úteis para configurá-los como abordagens opostas.

Palavras-chave: Teatro de animação tradicional; aprendizado com performances tradicionais; tradição um portal para a inovação

\section{Abstract}

What can be usefully said about tradition and innovation? This paper questions whether these terms are really the most useful in setting them up as opposing approaches.

Keywords: Theater of traditional animation; learning with traditional performances; tradition a gateway into innovation 
Eu não sou uma bonequeira tradicional na estreita compreensão do que isso significa; eu não dirijo um programa que se concentra principalmente na tradição do teatro de animação contemporâneo. Mas embora eu não seja uma bonequeira tradicional e não tenha treinado como uma, estou profundamente interessada no que é oferecido pelas práticas tradicionais, especialmente aquelas que vão além da forma em si, mas rumo aos conceitos mais amplos de teatro; e eu pessoalmente me inspiro em práticas tradicionais. E assim, minhas reflexões me levaram a quatro considerações principais:

\section{Primeiramente:}

- Deveríamos considerar alguns questionamentos acadêmicos sobre significados e entendimentos sobre tradição. Nessas reuniões, temos uma mistura de pensamento acadêmico e teórico, juntamente com relatos de trabalho de profissionais dentro da pedagogia e outros campos, que é o melhor tipo de intercâmbio frutífero. Então, minha contribuição aqui é adicionar algumas ideias acadêmicas a esse mix. Posso ser um pouco controversa, mas espero não ser ingênua sobre a tradição.

\section{Vamos pensar sobre tradição.}

Tenho dúvidas se essa divisão entre tradição e inovação é tão clara. Recentemente, eu me detive em conferências e reuniões de teatro de animação pela atenção que é dada às oposições binárias. Pergunto-me se essas divisões são realmente úteis. Aqui estamos discutindo a relação entre duas aparentes oposições: tradição e inovação. Em outra conferência recentemente, notei a atenção dada à definição das diferenças entre o teatro de animação oriental e ocidental. Talvez, em vez disso, pudéssemos olhar para os pontos de encontro e semelhanças. O teatro de animação tradicional já não é inovador? Punch e Judy é inovador? Sim! É tradicional? Sim! O mesmo acontece com as marionetes sicilianas Pupi e com Wayang, de diferentes regiões geográficas. Praticantes de formas tradicionais precisam inovar para sobreviver. A natureza da tradição é que, apesar das ligações estreitas com o ritual, religião e linhagem, geralmente responde às narrativas econômicas, culturais e políticas da contemporaneidade. Nosso desejo, no entanto, de identificar a diferença é natural. O teórico cultural materialista, Raymond Williams, nos diz que a tradição é sempre uma coisa viva baseada na "diferença habitual". Isso significa que a tradição é identificada pelo que a torna diferente de outras manifestações culturais. O que ele aponta, no entanto, é que a tradição nunca é estática.

Francis Mulhern sugere ainda que a tradição é "um processo através do qual as coletividades adaptam sua herança conforme as novas condições" (New Left Review, 2009). Já ouvimos como bonequeiros tradicionais estão fazendo isso: eles estão adaptando suas formas habituais para novos públicos, economia e contextos. Vários dos artigos publicados na publicação recente da Comissão de Pesquisa da UNIMA (Tracing Past and Present: International Puppetry Research, 2016) falam precisamente sobre esse fenômeno. A tradição é o ponto de encontro entre passado e futuro.

Nos estudos culturais, o teórico Stuart Hall nos diz que a tradição está sempre imersa em relações de poder: a cultura popular é inscrita com significados transgressivos, subversivos e, às vezes, repressivos (Cultural Studies, 1983). 
No teatro de animação não é diferente. Está claro que parte do posicionamento do teatro de animação na academia e nas artes está certamente ligado a formas culturais consideradas "eruditas" e "populares", como aquelas sobre o reposicionamento do teatro de animação na formação tcheca (Dolenska, 2017). Mais tarde, refletirei sobre isso no contexto britânico.

Assim, a operação da tradição não é um simples ato de repetição de forma; sociedade, política, economia e significado cultural estão profundamente conectados. A realização do teatro de animação tradicional, além disso, oferece grande flexibilidade e riqueza além da própria forma: a capacidade de improvisar e responder às circunstâncias atuais, o conteúdo de eventos políticos, o uso da tecnologia, enfim as autodefinidas qualidades inovadoras da própria tradição.

John McGrath, o crítico de teatro, nos diz que, por meio da tradição, "as sociedades questionam o mito de si mesmas" (A Good Night Out, 1981). Eu sugeriria, portanto, que a tradição já é uma atividade profundamente reflexiva e inovadora.

Acrescentarei os comentários de Gerd Baumann para quem "tradição é uma JAM session mutuamente improvisada" (The Multicultural Riddle, 1999).

A restauração, realização e realização das formas tradicionais pode levar às communitas, a palavra popularizada por Victor Turner (A Floresta dos Símbolos, 1967), para significar, em termos gerais, o senso de união experimentado por uma comunidade que passou por algo em conjunto. Esse senso de communitas é aprendido pela criança enquanto ela negocia seu lugar dentro da cultura. Isso é importante para a construção da identidade.

No entanto, é nos interstícios e rupturas da tradição que frequentemente surgem materiais interessantes.

Portanto, a conclusão deste ponto é sugerir que as tradições são política e culturalmente significativas; que tradição já é inovadora e que outro ponto de partida poderia ser procurar pontos de encontro existentes entre formas, em vez das diferenças.

Mais perguntas para compartilhar:

Quanto tempo leva, ou quantas vezes algo tem que ser repetido e em que contexto, para ser uma tradição?

O que é inovação?

A tradição só é percebida na construção do teatro de animação, no contexto social ou no conteúdo material? A tradição também poderia ser percebida no meio do mundo do teatro de animação e em sua relação com o público e outros mundos?

\section{Agora, para passar para o segundo ponto: o que realmente entendemos como tradição?}

Aqui eu falo particularmente da perspectiva do Reino Unido.

O Reino Unido agora está em crise. Essa crise está surgindo desde há muito tempo. O Reino Unido agora, mais intensamente do que há tempos atrás, está 
debatendo, interna e externamente, qual a sua identidade em relação ao nacionalismo, etnicidade, multiculturalismo e hegemonia mundial. A identidade britânica foi muito difundida entre alguns círculos como sendo multiculturalmente progressista, agora um debate enfurecido e cheio de ódio sobre o que significa ser britânico está ocorrendo. 80 pessoas de várias origens étnicas e culturais acabaram de morrer no incêndio de um edifício de habitação popular ${ }^{2}$, que sucessivos governos falharam em adequar aos padrões de segurança; outro dia um galês adotou o método de assassinato por atropelamento num ataque contra muçulmanos; MAS a primeira-ministra foi forçada a prometer humildade nas negociações do Brexit; a retórica do ódio dos governos e da mídia parece estar levando a um profundo reconhecimento de que a Grã-Bretanha é uma sociedade profundamente multicultural. Muitas gerações de imigrantes, baseadas em mais de 500 anos de colonização brutal, resultaram numa sociedade na qual a tradição já é híbrida.

Isso significa, portanto, que a tradição britânica de teatro de animação não se limita ao Punch e Judy. Vamos incluir nessa tradição de teatro de animação do Reino Unido as formas animadas do carnaval afro-caribenhos, teatros de sombra indianos, apresentados em todas as comunidades do Reino Unido, marionetes vitorianas e também, mas não exclusivamente, Punch e Judy. Essas formas animadas já estão em diálogo. Bonecos gigantes de Punch e Judy são usados nas celebrações de festivais e nos desfiles de carnaval; teatros de sombra indianos foram usados no passado na produção de "O jardim das cerejeiras", de Tchekhov. Não devemos ignorar as questões levantadas por Rustom Bharucha (Theatre and the World, 1993) e outras, em relação ao trabalho de Peter Brook, por exemplo, sobre a apropriação cultural, mas minha tese aqui é que já estamos vivendo em um mundo pós-tradicional, onde as formas não são susceptíveis de serem confinadas num grupo cultural, diaspórico e geográfico. Precisamos reconhecer a história e estar conscientes das múltiplas sobreposições, texturas e relações intertextuais entre formas culturais. Deixe-me voltar à minha pergunta sobre quanto tempo leva para que algo se torne tradicional.

A formidável companhia Welfare State International iniciou uma tradição de festivais de lanternas e desfiles de bonecos gigantes como parte das festividades de cultura popular por todo o país durante os anos 80 e agora, trinta anos depois, inúmeras vilas e cidades têm seus próprios desfiles ao longo do ano, que fazem referência ao carnaval afro-caribenho, aos bonecos gigantes da Catalunha e aos festivais ingleses de "obby" oss (eles próprios formas híbridas). Depois de dez, vinte anos, essas comunidades consideram suas performances tradicionais.

Do trabalho da companhia Handspring, na peça War Horse, e do estúdio Blind Summit e do English National Opera, está surgindo uma "tradição" de bonecos animais multi-manipulados, enquanto uma forma de arte "erudita". Podemos nos referir a isso como tradicional? Ou o tradicional é percebido apenas como existente nas formas de arte "popular"?

${ }^{2}$ Grenfell Tower 


\section{Em terceiro lugar: o que as formas tradicionais nos ensinam para além da forma e do conteúdo imediatos da própria tradição?}

Trabalhar com formas tradicionais pode nos permitir aprender outras maneiras de trabalhar. Não precisamos necessariamente usar as verdadeiras formas que aprendemos. Quando eu era estudante, aprendi a dança Chhau, da Índia. Depois de um único projeto intensivo e envolvente, nunca voltei à dança Chhau como performer ou praticante, mas o projeto instigou em mim um senso da importância da terra abaixo dos meus pés nas performances, da gravidade e do trabalho de máscara - todas as técnicas de treinamento que têm sido inestimáveis no teatro de animação.

Por meio do estudo de T'ai Chi, os alunos são capazes de experimentar a importância do fluxo de energia, resistência e equilíbrio; assim como todos os elementos- chave no treinamento em teatro de animação.

Ao estudar o treinamento psicofísico no teatro de Philip Zarrilli (Psychophysical Acting: 2008), que se baseia em Kalaripayattu, Kathakali e Tai'i Chi, os alunos se tornam conscientes da conexão mente-corpo na performance.

Estudando o Pupi italiano, os estudantes são capazes de experimentar o ritmo, a importância da performance do evento, a rotina, a teatralidade e como mudar as cabeças dos bonecos em uma performance.

Observando uma variedade de performances tradicionais, os alunos são capazes de perceber que o teatro de animação pode quebrar estruturas; bonecos nem sempre precisam respirar para emularem a vida; eles podem ser subversivos, estridentes, ridículos, enérgicos, mortos-vivos ao mesmo tempo, e que toda estética do "PORQUE OS BONECOS SÃO DIFERENTES" pode ser apreendida mais rápida e facilmente, inspirando-se não no teatro "humano", mas na arte, no grotesco, no microteatro, que muitas vezes levam a interações bem mais empolgantes.

Os alunos também aprendem que os bonecos podem e falam sobre gênero, raça, classe social e política. Isso não vem da chamada inovação da tradição "erudita", mas da longa tradição do teatro popular que comenta incessantemente seu próprio mundo. Certamente, isso levou, às vezes, a algumas fricções entre praticantes, acadêmicos e estudantes. Um debate enfurecido foi desencadeado há alguns anos entre alguns professores de Punch e Judy numa apresentação em que Punch era uma cross-dressing lésbica. (Watson in Tracing Past and Present, 2016)

$\mathrm{Na}$ pedagogia, os alunos muitas vezes querem saber e compreender rapidamente, embora o treinamento tradicional nem sempre ofereça uma compreensão rápida. Imersão em um processo é importante para a disciplina física. Mas dentro do frágil mundo do treinamento de teatro de animação em que estou envolvida, a questão da tradição versus inovação não surge. Não é possível para os estudantes não inovarem. Toda a premissa de sua existência como estudantes de teatro de animação é inovar usando quaisquer materiais e recursos à sua disposição. Eles não precisam ser encorajados. Poderíamos argumentar que essa propensão a assumir que eles são os criadores de um novo trabalho também está relacionada às tradições culturais do que se entende ser teatro bom: inovação acima da perfeição.

Quais são, então, esses pontos de encontro entre tradição e inovação? A tradição invoca entendimentos particulares: comunal, local, antigo, mitológico; a inovação invoca a estrutura pessoal, individual, autobiográfica e metanarrativa. 
Teatro é comunicação, drama, interação. Regras podem ser quebradas. Se elas não pudessem ser quebradas, não seriam regras.

Aqui estão alguns aspectos do treinamento tradicional que são importantes além da forma:

Expor-se; se preparar para o trabalho; fazer trabalho físico; respeitar o espaço e, talvez, o mais importante: ter devoção à forma animada. Tratá-las com respeito e lembrar-se de que estamos atuando para os deuses (ou o que quer que seja percebido além do imediato) - isso não é fácil em contextos ateus/agnósticos/anti-religiosos do Ocidente, onde devoção é presumida como algo religioso, mas devoção ao trabalho pode existir, quer se trate de bonecos de papel, teatro de objetos, silhuetas de couro do teatro de sombras, etc.

Assim, aprender a tradição também é aprender disciplina, que a atividade de fazer teatro leva tempo e devoção.

\section{Quarto: como a tradição pode ser usada na pedagogia do treinamento do teatro de animação do Reino Unido?}

Aqui volto a questões de política cultural na arte. O treinamento no teatro de animação no Reino Unido é frágil e pouco subvencionado. No ensino superior, o teatro de animação surgiu principalmente como resultado da paixão de alguns praticantes e estudiosos e geralmente é oferecido como um módulo opcional num programa mais amplo de Teatro ou Drama, ou ainda dentro da Cenografia ou da formação artística. Como muitos de vocês saberão, há uma graduação em teatro de animação em Londres, desde 1997. O curso tem a esquipe com apenas um membro permanente ligado, além de um grande número de profissionais visitantes em caráter temporário. Desde que estive lá, lutei continuamente por mais pessoal e recursos que cresceram bem pouco. Mas a Grã-Bretanha tem uma longa herança do Protestantismo que iniciou, há muitos séculos, o processo de abandonar a iconografia na religião e na arte, e isso levou a uma abordagem um tanto utilitarista do teatro. Teatro de animação, portanto, tem que ser visto como "útil".

E aqui temos a questão sobre arte "erudita" e "popular". Uma mentalidade dominante em relação ao treinamento no teatro de animação do Reino Unido, responde à interesses do teatro britânico em geral, que define as formas animadas como uma opção dentro do teatro "humano" e não como uma arte separada e independente. Isso, em parte, responde a oportunidades de trabalho: como é muito mais comum ter formas animadas como elementos de uma peça de teatro "humano" é mais fácil para os bonequeiros encontrarem trabalho dessa maneira. Há um outro ponto, no entanto: o ímpeto de bonequeiros e do Conselho de Artes de melhorar o status do teatro de animação. Isso significou um afastamento das formas tradicionais em direção das chamadas formas de arte "eruditas", onde, definitivamente, as formas animadas encontraram status mais elevado e são importantes: nas produções do Teatro Nacional, que inclui a peça War Horse, com a Royal Shakespeare Company e com a English National Opera.

Isso até certo ponto levou a uma marginalização das formas populares. Minha própria perspectiva é que os estudantes de qualquer forma animada precisam saber de 
onde eles próprios vêm. Mas os estudantes não vêm exclusivamente do Reino Unido. Eles, portanto, tiveram que estudar no primeiro ano algumas formas tradicionais de teatro de animação e saber como usá-las em suas próprias performances. Isso não é para que eles repitam ou continuem com essas formas, mas para permitir uma maior compreensão de como funciona o teatro de animação. Estudar a tradição nos ensina como o teatro de formas animadas funciona. Acredito que todas as inovações que experimentamos no teatro de animação vieram de alguma forma dos ensinamentos da tradição.

Os projetos em que os estudantes são convidados a conhecer tanto a tradição quanto a inovação incluem: um projeto da UNIMA, intermediado por um grupo chamado Culture Studio, dirigido por British Asians, que consiste em uma troca digital com animadores-manipuladores indianos "tradicionais". Neste projeto, os alunos aprendem teatro de sombras via ensino à distância e por Skype; em seguida, eles trabalham com jovens artistas na criação de uma nova peça de formas animadas que fará uma turnê por Slough, uma comunidade multiétnica à oeste de Londres descrita como uma área carente. A forma tradicional será usada em novos meios de expressão e com jovens artistas em contextos sociais e culturais híbridos.

Outros estudantes estarão trabalhando numa performance de gênero, multicultural e questionadora, de Punch e Judy sobre Macbeth. Os alunos do primeiro ano farão bonecos gigantes para usar em desfiles carnavalescos que se baseiam em diversas tradições culturais no Reino Unido. Recentemente, outros estudantes realizaram espetáculos de sombras inspirados na tradição indiana em uma produção do The Empress em Londres, um espetáculo que desafia o legado do colonialismo.

Políticas culturais aqui são cruciais. Tradição em teatro de animação significa entender as técnicas e meios através dos quais a sociedade expressa e reflete (seguindo McGrath, anteriormente citado). Os estudantes serão inovadores. Nós não precisamos ensinar isso a eles. Então, para mim, a tradição é sempre um portal de entrada para a inovação.

Este texto traduzido, do inglês, por Carlos Eduardo da Silva, também se encontra publicado em inglês neste número do periódico. Doutorando pelo Programa de Pós-graduação em Literatura, Universidade Federal de Santa Catarina (UFSC). cae.silva@gmail.com

Recebido em: 26/06/2018

Aprovado em: 26/06/2018 